\title{
The Effect of Leaf Wetness on Phytophthora ramorum Zoospore Infection of Rhododendron 'Cunningham's White' and Viburnum tinus
}

\author{
Paul W. Tooley ${ }^{\dagger}$ and Marsha Browning \\ United States Department of Agriculture-Agricultural Research Service Foreign Disease-Weed Science Research Unit, \\ Ft. Detrick, MD 21702
}

\begin{abstract}
We performed studies using zoospore inoculum combined from nine isolates of Phytophthora ramorum and determined the effect of leaf wetness on infection of whole plants of Rhododendron 'Cunningham's White' and Viburnum tinus. The mean percentage of infected leaves for both host species increased gradually across a dew chamber moisture period of 1 to $6 \mathrm{~h}$, reaching approximately $80 \%$ infection by $6 \mathrm{~h}$. We also evaluated the effect of a postinoculation drying period on infectivity of the

drying period, Rhododendron 'Cunningham's White' sustained less than $40 \%$ infected leaves, whereas $V$. tinus had an infection rate of almost $75 \%$ infected leaves. Disease percentages for both host species declined sharply with drying periods longer than $30 \mathrm{~min}$. Knowledge of infectivity parameters for $P$. ramorum will provide a better understanding of epidemic development and lead to improved recommendations for control.
\end{abstract} two host species with zoospore inoculum. With a $30-$ min postinoculation

Keywords: drying, epidemiology, ramorum blight.

Phytophthora ramorum causes sudden oak death and is responsible for the death of millions of trees in coastal California and Oregon (Frankel and Palmieri 2014; Rizzo et al. 2002; Werres et al. 2001). It also has caused devastating losses to Japanese larch trees in much of the United Kingdom and parts of Ireland (Brasier and Webber 2010; Harris and Webber 2016; King et al. 2015). P. ramorum has a wide host range (USDA-APHIS 2012) and attacks numerous plant species important in the nursery industry, causing extensive losses (Dart and Chastagner 2007; Suslow 2006).

Sporangia are the primary type of asexual spore produced by Phytophthora spp. (Erwin and Ribeiro 1996), and they give rise to motile zoospores under specific temperature conditions. Zoospores are thought to be the primary infective propagule for many Phytophthora spp., due to their vast numbers, motility, and a proven ability to amass at sites of infection for root-infecting species (Hickman and Ho 1966; Raftoyannis and Dick 2006; Zentmyer 1961). However, in addition to their role in dispersal via wind and rain splash for Phytophthora spp. that largely infect aboveground plant parts (i.e., "aerial" species), sporangia are also capable of direct infection of host tissue (Erwin and Ribeiro 1996).

Foliar infection of $P$. ramorum hosts in nature is caused by sporangia and zoospores (Davidson et al. 2008). However, the specific contributions of sporangia versus zoospores in P. ramorum epidemiology within a given ecosystem are not known. Knowledge of the behavior of sporangia and zoospores and the conditions under which they infect susceptible hosts needs to be understood so that forces that drive epidemics can be better known. Zoospores are the infective propagule in many epidemics due to the existence of environmental conditions that favor their development (Erwin and Ribeiro 1996).

${ }^{\dagger}$ Corresponding author: P. W. Tooley; paul.tooley@ars.usda.gov

Mention of trade names or commercial products in this publication is solely for the purpose of providing specific information and does not imply recommendation or endorsement by the U.S. Department of Agriculture. USDA is an equal opportunity provider and employer.

The author(s) declare no conflict of interest.

Accepted for publication 15 March 2019.

This article is in the public domain and not copyrightable. It may be freely reprinted with customary crediting of the source. The American Phytopathological Society, 2019.
Also, knowledge of zoospore behavior is important for the nursery industry, in part because zoospores are thought to be the main propagule found in irrigation water (Charlton and von Broembsen 2000; Granke and Hausbeck 2010; Stanghellini et al. 1996). Thus, conditions for infection of susceptible hosts by zoospores need to be identified for a better understanding of epidemic dynamics.

Many previous studies with $P$. ramorum have used sporangia as the inoculum source (Tooley and Browning 2009; Tooley and Kyde 2007; Tooley et al. 2004, 2009, 2011) and conditions for infection via sporangia have been described (Tooley et al. 2009). It was observed that, for sporangial inoculation, 24 to $48 \mathrm{~h}$ of moisture was required to reach maximum levels of disease on both whole plants and detached leaves of Rhododendron 'Cunningham's White' (Tooley et al. 2009). With whole plants, the minimum period of moisture ( $100 \%$ relative humidity $[\mathrm{RH}]$ produced in a dew chamber) included as an experimental treatment and required to result in disease following 7 days incubation at $20^{\circ} \mathrm{C}$ was $1 \mathrm{~h}$. Determining whether the same moisture conditions applied to zoospore inoculation as for sporangia inoculation would contribute to an understanding of $P$. ramorum etiology and epidemiology.

Little is known of the effects of a drying period on infection of Phytophthora hosts with sporangia or zoospores. With $P$. colocasiae, sporangia viability was lost in less than 2 days when diseased leaves were allowed to dry in the shade (Trujillo 1964). Sporangia of $P$. parasitica also did not survive on air-dried leaves for more than $2 \mathrm{~h}$ (Kuske and Benson 1983). Knowledge of drying effects on P. ramorum etiology would provide a better understanding of how drought conditions in areas where the pathogen is now endemic (such as California) may affect disease spread and infection via sporangia and zoospores.

Zoospores of species such as $P$. infestans are generally considered more susceptible to the effects of environmental factors such as drying and UV radiation (McKee 1969; Porter and Johnson 2004) compared with sporangia. However, MacDonald and Duniway (1979) found that tolerance to desiccation of encysted zoospores varied considerably between $P$. megasperma and $P$. cinnamomi, indicating that species differences exist. The high numbers of zoospores produced by Phytophthora spp. under optimal conditions, along with their ability to enter stomates and other avenues of infection, lead some to consider them a more effective source of inoculum compared with sporangia. Widmer (2009), for example, has suggested that the full inoculation potential of $P$. ramorum may not be achieved when sporangia as opposed to zoospores are used as the inoculum propagule. 
In this study, we performed experiments to determine the period of leaf wetness required for infection of Rhododendron 'Cunningham's White' and Viburnum tinus following inoculation with $P$. ramorum zoospores, and to determine the effects of a postinoculation drying period on infection of the two host species by zoospores.

\section{Materials and Methods}

Nine isolates of $P$. ramorum were utilized in this study (Table 1), representing three different clonal lineages now found in North America (Grünwald et al. 2009). Cultures were maintained on buffered $10 \% \mathrm{~V} 8$-juice agar (100 $\mathrm{ml}$ of $\mathrm{V} 8$ juice, $3 \mathrm{~g}$ of calcium carbonate, and $20 \mathrm{~g}$ of agar per liter of the medium) at $20^{\circ} \mathrm{C}$ in the dark. Sporangia were produced by incubating plugs removed from approximately 10-day-old cultures in sterile $1 \%$ soil extract (Tooley et al. 2004) for $72 \mathrm{~h}$ at $20^{\circ} \mathrm{C}$ in darkness. Sporangia were chilled at $4^{\circ} \mathrm{C}$ for $45 \mathrm{~min}$ followed by treatment at room temperature for $45 \mathrm{~min}$ to allow zoospore release. Spore suspensions of the nine isolates were combined and then passed through a 53- $\mu \mathrm{m}$ mesh nylon screen to filter out sporangia. Zoospores passed through the screen, and their concentration was determined using a hemacytometer. Zoospores were then diluted to 50,000 zoospores $/ \mathrm{ml}$ with sterile $1 \%$ soil extract. Test plants were 2-year-old liners (young plants rooted in standard greenhouse trays) of Rhododendron 'Cunningham's White' and rooted cuttings $(<1$ year old) of $V$. tinus. These two host species were chosen because they are important in the nursery industry, are able to be grown and propagated successfully under greenhouse conditions, and represent genera that show susceptibility to $P$. ramorum in nature.

Effect of moisture period on infection. In all, 12 R. 'Cunningham's White' and 12 V. tinus plants were spray inoculated to runoff with the combined nine $P$. ramorum isolates at 50,000 zoospores $/ \mathrm{ml}$ (Table 1), and placed in a dew chamber at $20^{\circ} \mathrm{C}$ in darkness. Two randomly selected plants (replications) were removed from the dew chamber after $0,1,2,4$, and $6 \mathrm{~h}$ of incubation and placed on a greenhouse bench to allow the leaves to dry. After $1 \mathrm{~h}$ of drying, the plants were placed into plastic trays inside humidity tents (wooden frames covered with clear plastic sheeting on five sides, with an open bottom) situated on a greenhouse bench (average humidity 53\%). The tents were needed to compensate for low humidity levels and strong air currents present in the climate-controlled greenhouse. Water levels in the trays were maintained at a depth of approximately $1 \mathrm{~cm}$. Temperature and RH were monitored with HOBO (Onset Corp., Bourne, MA U.S.A.) data loggers. The remaining two plants were maintained in the dew chamber for 3 to 5 days to serve as positive controls. Following 3 days of incubation in the humidity tents, plants were evaluated for disease. All leaves displaying P. ramorum disease lesions were harvested and counted. Samples of diseased tissue from up to 10 leaves per plant were plated on PARPH-V8 agar (Ferguson and Jeffers 1999; Jeffers and Martin 1986) to confirm the presence of $P$. ramorum. Plants were then returned to dew chambers for an additional 4 days to allow the remaining asymptomatic leaves to develop lesions. Upon removal from dew, diseased leaves were once again collected and necrotic regions were plated. The total number of $P$. ramorum-infected leaves from both the humidity chamber incubation and the final dew chamber incubation was divided by the total number of inoculated leaves on each of the two replicate plants to yield the percent infected leaves for each treatment in each experiment. Seven independent replicate experiments were performed, each experiment containing 12 plants of each plant species in a completely random design.

Zoospore drying. Twenty-one plants of either Rhododendron 'Cunningham's White' or Viburnum tinus were spray inoculated with nine combined $P$. ramorum isolates at 50,000 zoospores $/ \mathrm{ml}$ as described above and left on a greenhouse bench to air dry. When leaf surfaces appeared to be dry, plants were transferred to a greenhouse bench humidity tent ( 47 to $48 \% \mathrm{RH}$ ) as described above. At $0,0.5,1$, $1.5,2,2.5$, and $3 \mathrm{~h}$ following inoculation, 3 of the 21 inoculated plants for each time point were transferred to dew chambers at $20^{\circ} \mathrm{C}$ in darkness. Thus, there were three replications per treatment. Time 0 represented positive controls. Only plants with dry foliage were selected after $0.5 \mathrm{~h}$. Following 5 days of incubation in the dew chambers, plants were evaluated for disease. Leaves with necrotic lesions were harvested and samples of diseased tissue were plated on PARP selective medium to confirm the presence of $P$. ramorum at a maximum of 10 leaves per plant. Five independent replicate experiments were completed with each plant species, utilizing 21 plants of the given species in each experiment in a completely random design.

Statistical analyses were performed using the general linear models and regression procedures in Minitab (Minitab Inc. 2010). In the moisture period experiments, 12 plants of each of the two plant species were included in each of the seven replicate experiments performed; thus, plant species could be used as a factor in the analysis of variance (ANOVA). Because 21 plants were included in each of the drying period experiments, replicate experiments needed to be performed separately for each plant species due to logistical considerations. Thus, the effect of the experiment factor in ANOVA could only be assessed within each plant species.

\section{Results}

Moisture period studies. Most infected leaves were obtained during the 3-day incubation in the greenhouse but more infected leaves resulting from the additional 4 days in dew were added to make the total percentage of diseased leaves (Fig. 1). Highest numbers of infected leaves resulting from the additional 4 days in dew were observed at the 2- and 4-h moisture periods (Fig. 1). The percentage of infected leaves increased gradually over the 1- to 6-h moisture periods, reaching approximately $80 \%$ infection by $6 \mathrm{~h}$. Mean infection levels in positive control plants that were maintained in a dew chamber for 3 to 5 days were 98 to $99 \%$.

ANOVA based on the number of infected leaves at each moisture period was performed to determine the effects of moisture period on infection of the two host species by zoospores of $P$. ramorum (Table 2). A significant $(P<0.05)$ difference was observed for plant species (Rhododendron 'Cunningham's White' versus V. tinus), while highly significant differences $(P<0.01)$ were observed for experiments and hours (Table 2). The adjusted $R^{2}$ statistic for the ANOVA was $84.4 \%$, indicating a good fit of the data to the chosen

Table 1. Isolates of Phytophthora ramorum used in this study

\begin{tabular}{|c|c|c|c|c|}
\hline Isolate $^{\mathbf{a}}$ & Host & Location & Year isolated & Clonal lineage ${ }^{b}$ \\
\hline 1772 & Viburnum 'Mariesii' & Oregon & 2003 & NA1 \\
\hline NS-5C & Camellia sasanqua 'Bonanza' & California & 2003 & NA1 \\
\hline $107-0093$ & Rhododendron 'Christmas Cheer' & Washington & 2007 & NA1 \\
\hline $05-166$ & Rhododendron & Washington & 2004 & NA2 \\
\hline $09-053$ & Rhododendron & California & Unknown & NA2 \\
\hline $109-0074$ & Gaultheria shallon & Washington & 2009 & NA2 \\
\hline PRG-2 = BBA 9/95 & Rhododendron catawbiense & Germany & 1995 & EU1 \\
\hline $06-021$ & Pieris japonica & Oregon & 2006 & EU1 \\
\hline $109-0058$ & Rhododendron 'Dexter's Pink' & Washington & 2009 & EU1 \\
\hline
\end{tabular}

${ }^{\text {a }}$ Sporangia were chilled at $4{ }^{\circ} \mathrm{C}$ for $45 \mathrm{~min}$ followed by treatment at room temperature for $45 \mathrm{~min}$ to allow zoospore release. Spore suspensions of the nine isolates were combined and then passed through a 53- $\mu \mathrm{m}$ mesh nylon screen to filter out sporangia prior to inoculation.

${ }^{\mathrm{b}}$ Clonal lineage as described by Grünwald et al. 2009. 
model. Residual plots showed no deviations from the assumptions underlying the ANOVA analysis.

To determine the relationship for the total number of infected leaves in response to increasing moisture period, we performed regression using the data from the 0 - to 6-h moisture periods. The best fit to the data was a polynomial function containing linear and quadratic terms, with the overall regression over both host plant species combined of total percent diseased leaves $=2.054+32.06 \mathrm{~h}-3.074$ $\mathrm{h}^{2}$ (with an adjusted $R^{2}$ of $66.3 \%$ ). For Rhododendron 'Cunningham's White' alone, the equation was total percent diseased leaves = $3.025+35.57 \mathrm{~h}-3.680 \mathrm{~h}^{2}$ (with an adjusted $R^{2}$ of $68.9 \%$ ) whereas, for $V$. tinus, the equation was total percent diseased leaves = $1.084+28.56 \mathrm{~h}-2.467 \mathrm{~h}^{2}$ (with an adjusted $R^{2}$ of $64.4 \%$ ).
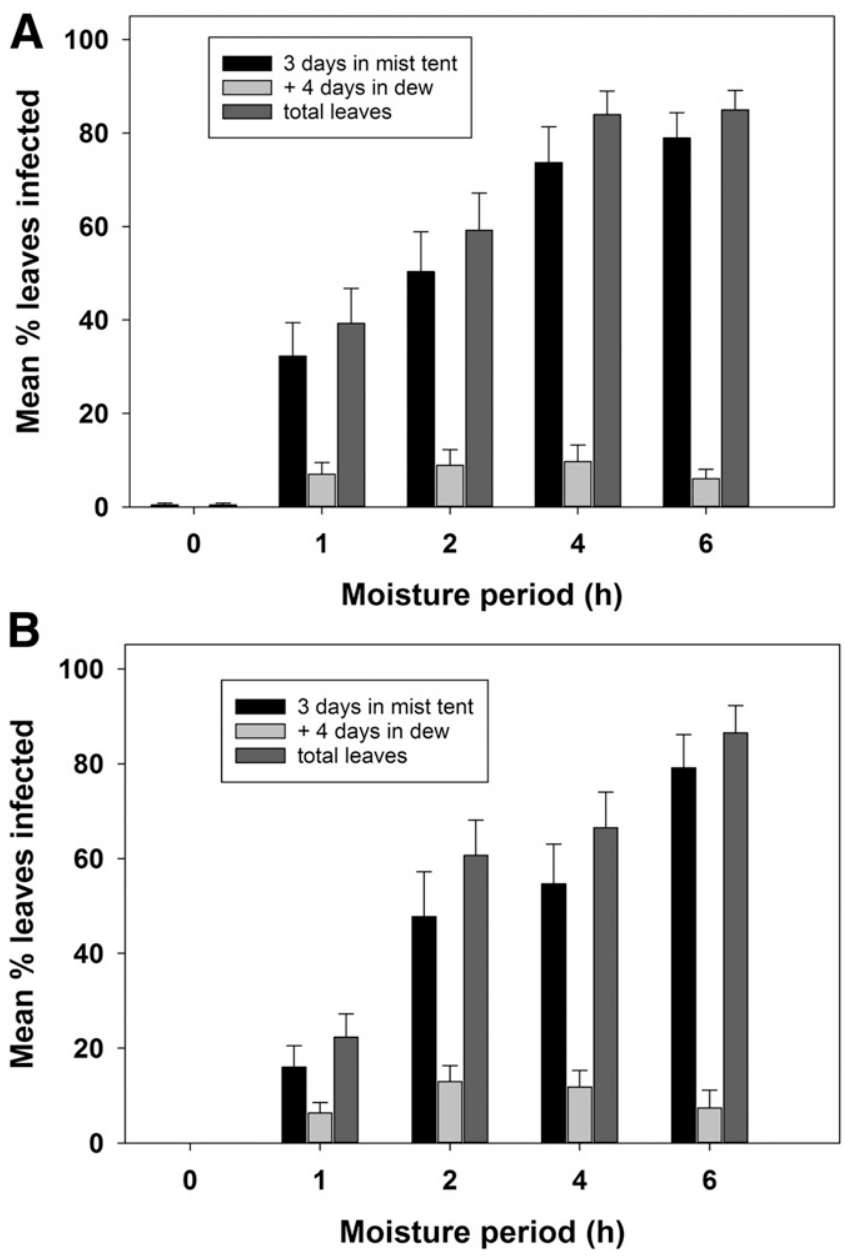

Fig. 1. Effect of moisture period duration on infection of leaves of $\mathbf{A}$, Rhododendron 'Cunningham's White' and B, Viburnum tinus, by zoospores of nine combined isolates of Phytophthora ramorum. Bars represent standard errors.

Table 2. Analysis of variance (ANOVA) table for moisture period ${ }^{\mathrm{a}}$

\begin{tabular}{lrrrcc}
\hline Source & df & Adj SS & Adj MS & \multicolumn{1}{c}{$\boldsymbol{F}$} & $\boldsymbol{P}$ \\
\hline Experiment & 6 & 17,484 & $2,913.9$ & 8.46 & 0.000 \\
Plant & 1 & 1,408 & $1,408.1$ & 4.09 & 0.045 \\
Hours & 4 & 136,148 & $34,037.1$ & 98.79 & 0.000 \\
Plant $\times$ hours & 4 & 2,764 & 691.1 & 2.01 & 0.098 \\
Error & 124 & 42,722 & 344.5 & $\ldots$ & $\ldots$ \\
Lack-of-fit & 54 & 26,919 & 498.5 & 2.21 & 0.001 \\
Pure error & 70 & 15,803 & 225.8 & $\ldots$ & $\ldots$ \\
Total & 139 & 200,527 & $\ldots$ & $\ldots$ & $\ldots$ \\
\hline
\end{tabular}

a The overall adjusted $R^{2}$ for the ANOVA analysis was $76.1 \%$. Columns: $\mathrm{df}=$ degrees of freedom, Adj SS = adjusted sum of squares, Adj MS = adjusted mean square, $F=F$ statistic, and $P=$ probability level.
ANOVA results from polynomial regression analysis for the two hosts, including the linear and quadratic terms and their significance levels, are shown in Table 3. The polynomial regression line fit to the data is shown in Figure 2.

Zoospore drying studies. There was a marked effect of drying period between inoculation and dew chamber incubation on the percentage of leaves infected by zoospores of P. ramorum (Fig. 3). For treatments that consisted of no drying period, nearly $100 \%$ of

Table 3. Polynomial regression analysis for total percent diseased leaves as a function of moisture period ( 0 to $6 \mathrm{~h}$ ) for infection of Rhododendron 'Cunningham's White' and Viburnum tinus by zoospores of Phytophthora ramorum $^{\mathrm{a}}$

\begin{tabular}{lccccc}
\hline Source & df & SS & MS & $\boldsymbol{F}$ & $\boldsymbol{P}$ \\
\hline Rhododendron & & & & & \\
$\quad$ Regression & 2 & $69,162.8$ & $34,581.4$ & 77.35 & 0.000 \\
$\quad$ Linear & 1 & $56,896.7$ & $\ldots$ & 91.64 & 0.000 \\
Quadratic & 1 & $12,266.1$ & $\ldots$ & 27.44 & 0.000 \\
$\quad$ Error & 67 & $29,954.8$ & 447.1 & $\ldots$ & $\ldots$ \\
$\quad$ Total & 69 & $99,117.5$ & $\ldots$ & $\ldots$ & $\ldots$ \\
V. tinus & & & & & \\
$\quad$ Regression & 2 & 65,464 & $32,731.9$ & 63.50 & 0.000 \\
Linear & 1 & $59,952.7$ & $\ldots$ & 101.80 & 0.000 \\
Quadratic & 1 & $5,511.1$ & $\ldots$ & 10.69 & 0.002 \\
Error & 67 & 34,537 & 515.5 & $\ldots$ & $\ldots$ \\
$\quad$ Total & 69 & 100,001 & $\ldots$ & $\ldots$ & $\ldots$ \\
\hline
\end{tabular}

a For Rhododendron 'Cunningham's White', the adjusted $R^{2}$ was $68.9 \%$; for Viburnum tinus, it was $64.4 \%$. Columns: $\mathrm{df}=$ degrees of freedom, $\mathrm{SS}=$ sum of squares, $\mathrm{MS}=$ mean square, $F=F$ statistic, and $P=$ probability level.
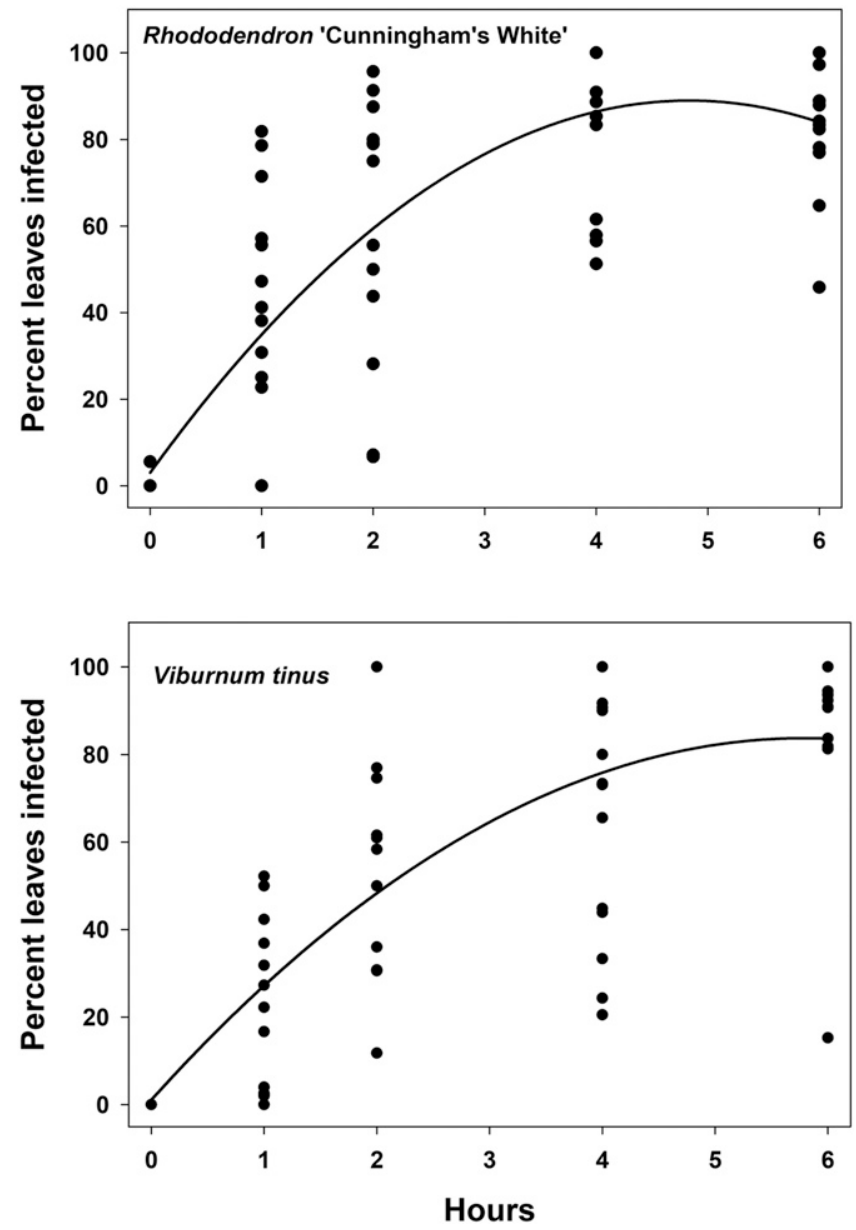

Fig. 2. Polynomial regression analysis for Rhododendron 'Cunningham's White' and Viburnum tinus for the moisture period analysis. 
leaves of both host plant species became infected. With a 30-min drying period (Fig. 3), Rhododendron 'Cunningham's White' sustained less than $40 \%$ visible infection, whereas $V$. tinus sustained almost $75 \%$ visible infection. The proportion of infected leaves for both species declined sharply after drying periods of longer than $30 \mathrm{~min}$ (Fig. 3 ). We observed that a period of 30 to 45 min was required for the moisture applied via spray inoculation to evaporate fully from both the upper and lower leaf surfaces in the well-ventilated greenhouse; therefore, the period of time that zoospores were actually subjected to drying was less than the "dry" exposure period treatment. ANOVA was performed to determine the effects of drying period on infection of the two host species by zoospores of $P$. ramorum. ANOVA was performed separately for each host species because both species were not included in the drying period experiments as they were for the moisture period experiments. Instead, five replicated, independent experiments were performed with each host species separately (Table 4). For Rhododendron 'Cunningham's White', highly significant $(P<0.01)$ main effects of experiment and drying time were observed, and the adjusted $R^{2}$ was $87.0 \%$. For $V$. tinus, highly significant $(P<0.01)$ main effects of experiment and drying time were observed and the experiment-drying time interaction term was also highly significant. The adjusted $R^{2}$ statistic was $97.9 \%$ (Table 4). To assess whether host species differed in the drying

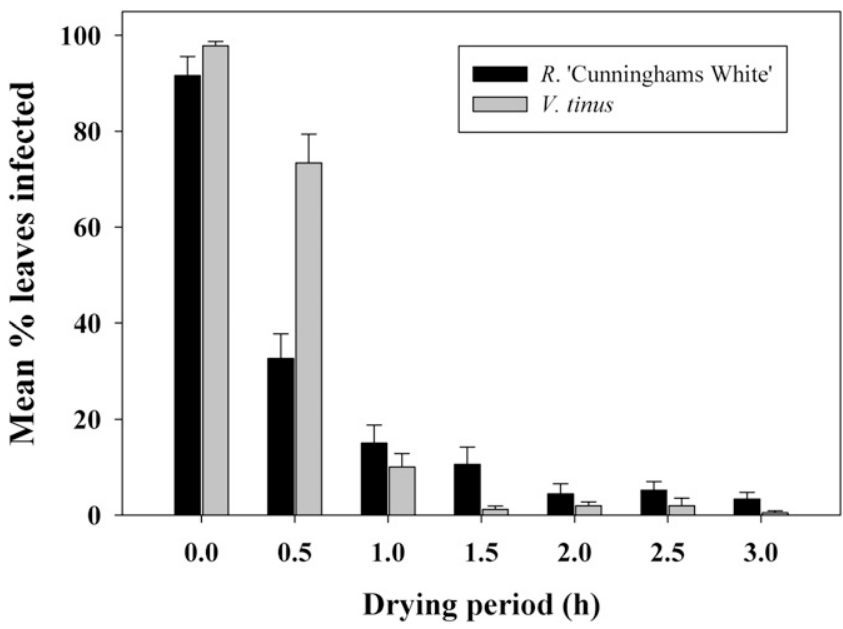

Fig. 3. Effect of drying between inoculation and dew chamber incubation on foliar infection of Rhododendron 'Cunningham's White' and Viburnum tinus by zoospores of nine combined isolates of Phytophthora ramorum. Bars represent standard errors.

Table 4. Analysis of variance (ANOVA) table for drying period ${ }^{\mathrm{a}}$

\begin{tabular}{lrrrrc}
\hline Source & df & Adj SS & Adj MS & $\boldsymbol{F}$ & $\boldsymbol{P}$ \\
\hline Rhododendron & & & & & \\
$\quad$ Experiment & 4 & 3,660 & 914.9 & 6.80 & 0.000 \\
Dry time & 6 & 91,001 & $15,166.9$ & 112.79 & 0.000 \\
Experiment $\times$ dry time & 24 & 3,584 & 149.3 & 1.11 & 0.356 \\
$\quad$ Error & 70 & 9,413 & 134.5 & $\ldots$ & $\ldots$ \\
$\quad$ Total & 104 & 107,657 & $\ldots$ & $\ldots$ & $\ldots$ \\
V. tinus & & & & & \\
Experiment & 4 & 2,014 & 503.6 & 15.50 & 0.000 \\
Dry time & 6 & 151,146 & $25,191.1$ & 775.48 & 0.000 \\
Experiment $\times$ dry time & 24 & 5,856 & 244.0 & 7.51 & 0.000 \\
Error & 70 & 2,274 & 32.5 & $\ldots$ & $\ldots$ \\
Total & 104 & 161,291 & $\ldots$ & $\ldots$ & $\ldots$ \\
\hline
\end{tabular}

${ }^{a}$ Because 21 plants were included in each drying period experiment, replicate experiments were performed separately for each plant species due to logistical considerations. Thus, the effect of the experiment factor in the ANOVA could only be assessed within each plant species. The adjusted $R^{2}$ for the Rhododendron 'Cunningham's White' ANOVA was $87.0 \%$, while that for Viburnum tinus was $97.9 \%$. Columns: $\mathrm{df}=$ degrees of freedom, Adj SS $=$ adjusted sum of squares, Adj MS = adjusted mean square, $F=F$ statistic, and $P=$ probability level. period analysis, another ANOVA was run using plant species as a factor but without experiment as a factor, because the two species were run in different sets of experiments. Significant effects of host plant species were observed $(P=0.05)$, and highly significant effects of drying time were noted $(P<0.001)$ (data not shown). The adjusted $R^{2}$ statistic for the analysis was $89.4 \%$, indicating a very good fit of the data to the chosen model. Residual plots showed no deviations from the assumptions underlying the ANOVA analyses.

The relationship between the percentage of leaves infected and drying time for both hosts combined was best described by a cubic equation, which fit better (via adjusted $R^{2}$ statistic) than linear or quadratic models. The best-fitting cubic equation in an analysis that included both hosts combined was percent infected leaves $=96.63-$ 124.3 drying time +53.63 drying time ${ }^{2}-7.554$ drying time $^{3}$, with an adjusted $R^{2}$ statistic of $83.9 \%$. For Rhododendron 'Cunningham's White' alone, the best-fitting cubic equation was percent infected leaves $=89.30-132.8$ drying time +68 drying time ${ }^{2}-11.15$ drying time $^{3}$ (adjusted $R^{2} 82.9 \%$ ). For $V$. tinus alone, the equation was percent infected leaves $=104-115.8$ drying time +39.26 drying time ${ }^{2}-$ 3.954 drying time ${ }^{3}$ (adjusted $R^{2}=87.8 \%$ ). ANOVA results from polynomial regression analysis for the two hosts, including the linear, quadratic, and cubic terms and their significance levels, are shown in Table 5. The best-fitting polynomial regression curve along with the data points are shown in Figure 4.

\section{Discussion}

In this study, we determined the period of leaf wetness required for infection of Rhododendron 'Cunningham's White' and V. tinus following inoculation with $P$. ramorum zoospores. A 2-h period of leaf wetness resulted in visible symptom development in approximately $60 \%$ of leaves with both Rhododendron 'Cunningham's White' and V. tinus (Fig. 1A and B, respectively). Tooley et al. (2009) showed previously that, using sporangia as the inoculum source for dip inoculation of whole Rhododendron 'Cunningham's White' plants, a dew period as short as $1 \mathrm{~h}$ (the minimum period tested) resulted in a low level of disease following 7 days of incubation at $20^{\circ} \mathrm{C}$. However, it took at least $4 \mathrm{~h}$ of dew for more than $10 \%$ of the leaves to become diseased. In contrast, with zoospore inoculum, we observed high levels of disease (approximately $40 \%$ of leaves infected) after as little as $1 \mathrm{~h}$ of dew period, and up to $80 \%$ infection after $4 \mathrm{~h}$ of dew.

The direct effects of drying on zoospores of various Phytophthora spp. have been examined by several workers. Drying of encysted zoospores of $P$. megasperma and $P$. cinnamomi was studied by MacDonald and Duniway (1979), who found that survival was dependent on water potential, and that tolerance to desiccation varied considerably between the two species. Stack and Millar (1985) showed

Table 5. Polynomial regression analysis for total percent diseased leaves as a function of drying period ( 0 to $3 \mathrm{~h}$ ) on infection of Rhododendron 'Cunningham's White' and Viburnum tinus by zoospores of Phytophthora ramorum ${ }^{\mathrm{a}}$

\begin{tabular}{lrcccc}
\hline Source & df & SS & MS & $\boldsymbol{F}$ & $\boldsymbol{P}$ \\
\hline Rhododendron & & & & & \\
$\quad$ Regression & 3 & 89,762 & $29,920.6$ & 168.87 & 0.000 \\
Linear & 1 & $58,468.4$ & $\ldots$ & 122.43 & 0.000 \\
Quadratic & 1 & $24,996.2$ & $\ldots$ & 105.39 & 0.000 \\
Cubic & 1 & $6,297.2$ & $\ldots$ & 35.54 & 0.000 \\
Error & 101 & 17,896 & 177.2 & $\ldots$ & $\ldots$ \\
$\quad$ Total & 104 & 107,657 & $\ldots$ & $\ldots$ & $\ldots$ \\
V. tinus & & & & & \\
Regression & 3 & 142,158 & $47,386.1$ & 250.15 & 0.000 \\
Linear & 1 & 105,080 & $\ldots$ & 192.55 & 0.000 \\
Quadratic & 1 & 36,287 & $\ldots$ & 185.77 & 0.000 \\
Cubic & 1 & 792 & $\ldots$ & 4.18 & 0.044 \\
Error & 101 & 19,133 & 189.4 & $\ldots$ & $\ldots$ \\
Total & 104 & 161,291 & $\ldots$ & $\ldots$ & $\ldots$ \\
\hline
\end{tabular}

${ }^{a}$ For Rhododendron 'Cunningham's White', the adjusted $R^{2}$ was $82.9 \%$; for $V$. tinus, it was $87.8 \%$. Columns: $\mathrm{df}=$ degrees of freedom, $\mathrm{SS}=$ sum of squares, $\mathrm{MS}=$ mean square, $F=F$ statistic, and $P=$ probability level. 
that zoospores of $P$. megasperma from alfalfa survived well in an abbreviated bioassay which involved adding water to soil, adding alfalfa seedlings as baits, and plating on selective medium 3 days later. However, use of an extended bioassay which involved first drying the soil for 7 days followed by a 3-day moistening period resulted in dramatically reduced activity. Zoospores of $P$. palmivora were placed in soil at different levels of moisture and viability determined using cacao pod isolations (Turner 1965). After 10 days, only half of the air-dried samples contained viable propagules. Encysted zoospores of $P$. cryptogea were able to germinate after 14 days on moistened forest soil at $25^{\circ} \mathrm{C}$ (Bumbieris 1979). Davidson et al. (2002) showed that $P$. ramorum chlamydospores and zoospores placed in suspension on filter paper were killed by drying for $30 \mathrm{~min}$ at $30 \% \mathrm{RH}$ but that, under moist conditions, they could survive for at least 1 month.

In addition to determining the leaf wetness required for infection, we characterized the effects of a postinoculation drying period of up to $3 \mathrm{~h}$ on infection of whole plants of the two host species by zoospores of $P$. ramorum. The effects of drying time on foliar infection by both host species were substantial, as indicated from the highly significant effects observed in the ANOVA analyses (Table 4), and the two plant hosts responded differently to drying time. Differences among hosts in the effects of drying on infection by $P$. ramorum zoospores could be caused by several factors, including susceptibility of the host tissue, frequency of stomatal openings that could allow infection to occur, or phenology of the leaf surface allowing better zoospore survival during dry periods. Infection of Rhododendron 'Cunningham's White' by zoospores dropped off much more quickly than that for $V$. tinus, perhaps indicating that, on the smoother Rhododendron leaves, zoospores were more susceptible to drying effects
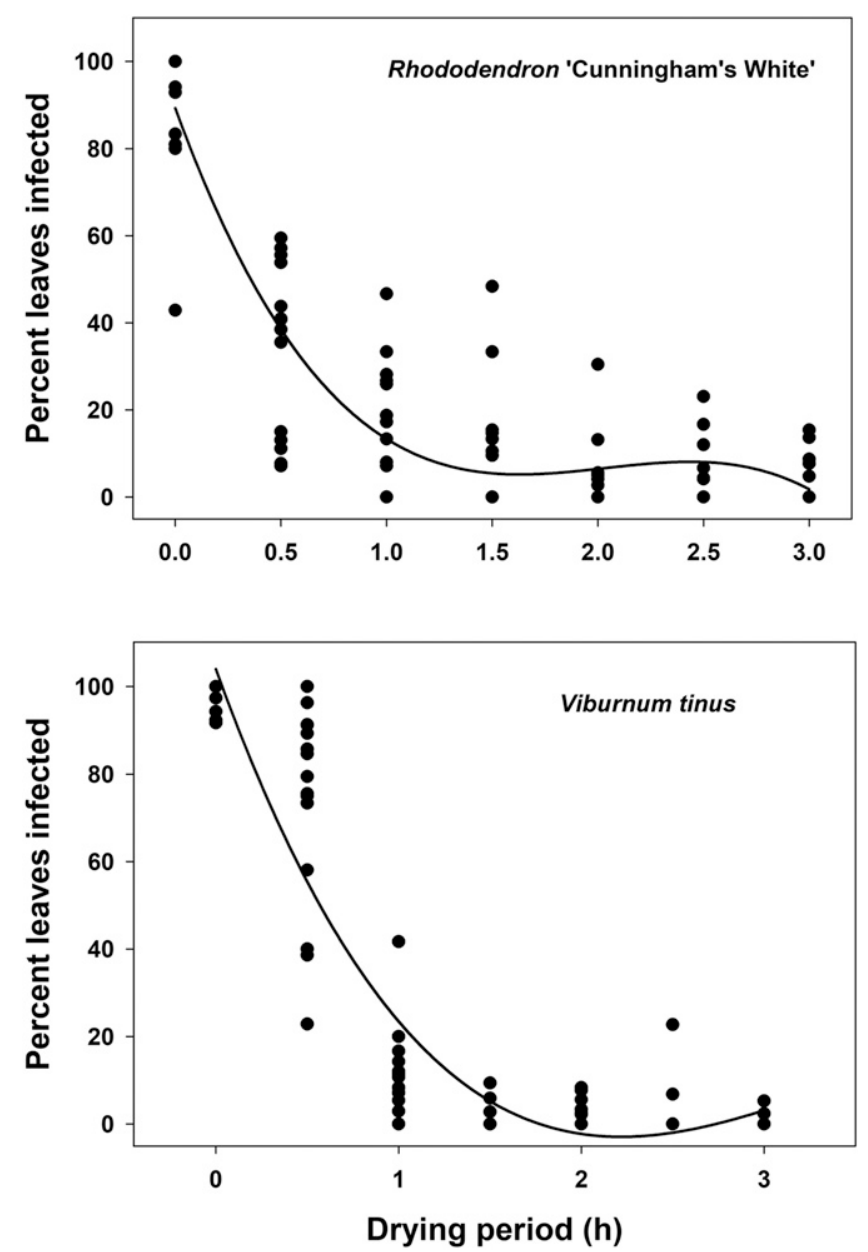

Fig. 4. Polynomial regression analysis for Rhododendron 'Cunningham's White' and Viburnum tinus for the drying period analysis. compared with rougher leaves that might conserve moisture in the more uneven leaf surface of $V$. tinus. Zoospores could also be better protected from the deleterious effects of ultraviolet radiation by being sheltered in crevices on rough leaf surfaces, and escape radiation which has been shown to be damaging to $P$. infestans sporangia (McKee 1969).

We found that infection percentages for both host species inoculated with $P$. ramorum zoospores dropped off sharply at postinoculation drying periods longer than $30 \mathrm{~min}$. As mentioned above, sporangia viability of $P$. colocasiae was lost in less than 2 days when inoculated leaves were allowed to dry in the shade (Trujillo 1964), and sporangia of $P$. parasitica did not survive on air-dried leaves for more than $2 \mathrm{~h}$ (Kuske and Benson 1983). The discovery that infection percentage by zoospores drops off so quickly with a drying period has ramifications for $P$. ramorum management recommendations. Commercial nurseries could strive to create dry periods during routine operations through ventilation or other means to reduce the likelihood that any $P$. ramorum inoculum present in the form of zoospores would have a chance of infecting susceptible hosts.

In summary, zoospores of $P$. ramorum can infect hosts in a shorter period of time than can sporangia, and are very susceptible to the effects of postinoculation drying. These findings add to our knowledge of the variables that affect and contribute to successful infection of plant hosts by $P$. ramorum, and will be useful in management recommendations (Griesbach et al. 2011; Suslow 2008) that seek to minimize the impact of $P$. ramorum in a nursery setting. Drying of foliage for at least $30 \mathrm{~min}$ may substantially reduce infection by $P$. ramorum were zoospore inoculum to be present in commercial greenhouses or shipping containers. Our findings may also be useful for pest risk assessment efforts (Cave et al. 2005; Sansford et al. 2010). Future research should be directed at determining the factors affecting zoospore discharge by sporangia in $P$. ramorum to understand the conditions under which zoospores are released in nature, resulting in increased inoculum potential capable of producing disease epidemics on susceptible hosts in nursery and forest environments.

\section{Literature Cited}

Brasier, C., and Webber, J. 2010. Sudden larch death. Nature 466:824-825.

Bumbieris, M. 1979. Aspects of the biology of Phytophthora cryptogea. Aust. J. Bot. 27:11-16.

Cave, G. L., Randall-Schadel, B., and Redlin, S. C. 2005. Risk Analysis for Phytophthora ramorum Werres, deCock \& In't Veld, causal agent of Phytophthora canker (sudden oak death), ramorum leaf blight, and ramorum die-back. USDA-APHIS-PPQ Center for Plant Health Science and Technology, Plant Epidemiology and Risk Analysis Laboratory, Raleigh, NC, U.S.A.

Charlton, N. D., and von Broembsen, S. L. 2000. Survival, settling, and lateral dispersal of encysted zoospores of Phytophthora spp. in captured irrigation runoff. (Abstr.) Phytopathology 90:S13.

Dart, N. L., and Chastagner, G. A. 2007. Estimated economic losses associated with the destruction of plants due to Phytophthora ramorum quarantine efforts in Washington State. Plant Health Prog. 8. doi:10.1094/PHP-20070508-02-RS

Davidson, J. M., Patterson, H. A., and Rizzo, D. M. 2008. Sources of inoculum for Phytophthora ramorum in a redwood forest. Phytopathology 98:860-866.

Davidson, J. M., Rizzo, D. M., Garbelotto, M., Tjosvold, S., and Slaughter, G. W. 2002. Phytophthora ramorum and sudden oak death in California: II. Transmission and survival. U. S. Dep. Agric. For. Serv. Gen. Tech. Rep. PSW-GTR-184:741-749.

Erwin, D. C., and Ribeiro, O. K. 1996. Phytophthora Diseases Worldwide. American Phytopathological Society, St. Paul, MN, U.S.A.

Ferguson, A. J., and Jeffers, S. N. 1999. Detecting multiple species of Phytophthora in container mixes from ornamental crop nurseries. Plant Dis. 83:1129-1136.

Frankel, S. J., and Palmieri, K. M. 2014. Sudden oak death, Phytophthora ramorum: A persistent threat to oaks and other tree species. Int. Oaks 25:43-56.

Granke, L. L., and Hausbeck, M. K. 2010. Effects of temperature, concentration, age, and algaecides on Phytophthora capsici zoospore infectivity. Plant Dis. 94:54-60.

Griesbach, J. A., Parke, J. L., Chastagner, G. A., Grünwald, N. J., and Aguirre, J. 2011. Safe Procurement and Production Manual: A Systems Approach for the Production of Healthy Nursery Stock. Oregon Association of Nurseries, Wilsonville, OR, U.S.A.

Grünwald, N. J., Goss, E. M., Ivors, K., Garbelotto, M., Martin, F. N., Prospero, S., Hansen, E., Bonants, P. J. M., Hamelin, R. C., Chastagner, G., Werres, S., Rizzo, D. M., Abad, G., Beales, P., Bilodeau, G. J., Blomquist, C. L., 
Brasier, C., Brière, S. C., Chandelier, A., Davidson, J. M., Denman, S., Elliott, M., Frankel, S. J., Goheen, E. M., de Gruyter, H., Heungens, K., James, D., Kanaskie, A., McWilliams, M. G., Man in 't Veld, W., Moralejo, E., Osterbauer, N. K., Palm, M. E., Parke, J. L., Perez Sierra, A. M., Shamoun, S. F., Shishkoff, N., Tooley, P. W., Vettraino, A. M., Webber, J., and Widmer, T. L. 2009. Standardizing the nomenclature for clonal lineages of the sudden oak death pathogen, Phytophthora ramorum. Phytopathology 99: 792-795.

Harris, A. R., and Webber, J. F. 2016. Sporulation potential, symptom expression and detection of Phytophthora ramorum on larch needles and other foliar hosts. Plant Pathol. 65:1441-1451.

Hickman, C. J., and Ho, H. H. 1966. Behavior of zoospores in plant pathogenic phycomycetes. Annu. Rev. Phytopathol. 4:195-214.

Jeffers, S. N., and Martin, S. B. 1986. Comparison of two media selective for Phytophthora and Pythium species. Plant Dis. 70:1038-1043.

King, K. M., Harris, A. R., and Webber, J. F. 2015. In planta detection used to define the distribution of the European lineages of Phytophthora ramorum on larch (Larix) in the UK. Plant Pathol. 64:1168-1175.

Kuske, C. R., and Benson, D. M. 1983. Overwintering and survival of Phytophthora parasitica, causing dieback of rhododendron. Phytopathology 73:1192-1196.

MacDonald, J. D., and Duniway, J. M. 1979. Use of fluorescent antibodies to study the survival of Phytophthora megasperma and P. cinnamomi zoospores in soil. Phytopathology 69:436-441.

McKee, R. K. 1969. Effects of ultraviolet irradiation on zoospores of Phytophthora infestans. Trans. Br. Mycol. Soc. 52:281-291.

Minitab, Inc. 2010. Minitab 17 Statistical Software. Minitab, Inc., State College, PA, U.S.A. http://www.minitab.com/en-us/

Porter, L. D., and Johnson, D. A. 2004. Survival of Phytophthora infestans in surface water. Phytopathology 94:380-387.

Raftoyannis, Y., and Dick, M. W. 2006. Zoospore encystment and pathogenicity of Phytophthora and Pythium species on plant roots. Mycol. Res. 161:1-8.

Rizzo, D. M., Garbelotto, M., Davidson, J. M., Slaughter, G. W., and Koike, S. T. 2002. Phytophthora ramorum as the cause of extensive mortality of Quercus spp. and Lithocarpus densiflorus in California. Plant Dis. 86:205-214.

Sansford, C., Inman, A., and Webber, J. 2010. Development of a pest risk analysis for Phytophthora ramorum for the European Union; the Key Deliverable from the EU Funded Project RAPRA. Pages 139-153 in: Proc. Sudden Oak Death Fourth Sci. Symp. S. J. Frankel, J. T. Kliejunas, and K. M. Palmieri, eds. 2010. Gen Tech. Rep PSW-GTR-229. U.S. Department of Agriculture, Forest Service, Pacific Southwest Research Station, Albany, CA, U.S.A.

Stack, J. P., and Millar, R. L. 1985. Relative survival potential of propagules of Phytophthora megasperma f. sp. medicaginis. Phytopathology 75: 1398-1404.
Stanghellini, M. E., Kim, D. H., Rasmussen, S. L., and Rorabaugh, P. A. 1996. Control of root rot of peppers caused by Phytophthora capsici with a nonionic surfactant. Plant Dis. 80:1113-1116.

Suslow, K. 2006. Phytophthora ramorum - Economic impacts and challenges for the nursery industry. Pages 41-44 in: Proc. Sudden Oak Death Second Sci. Symp.: State of our Knowledge. S. J. Frankel, P. J. Shea, and M. I. Haverty, eds. Gen. Tech. Rep. PSW-GTR-196. U.S. Department of Agriculture, Forest Service, Pacific Southwest Research Station, Albany, CA, U.S.A.

Suslow, K. 2008. Recommended industry best management practices for the prevention of Phytophthora ramorum introduction in nursery operations. Pages 115-128 in: Proc. Sudden Oak Death Third Sci. Symp. S. J. Frankel, J. T. Kliejunas, and K. M. Palmieri, tech. coords. Gen. Tech. Rep. PSWGTR-214. U.S. Department of Agriculture, Forest Service, Pacific Southwest Research Station, Albany, CA, U.S.A.

Tooley, P. W., and Browning, M. 2009. Susceptibility to Phytophthora ramorum and inoculum production potential of some common eastern forest understory plant species. Plant Dis. 93:249-256.

Tooley, P. W., Browning, M., Kyde, K. L., and Berner, D. 2009. Effect of tempera ture and moisture period on infection of Rhododendron 'Cunningham's White' by Phytophthora ramorum. Phytopathology 99:1045-1052.

Tooley, P. W., Browning, M., and Leighty, R. M. 2011. Infectivity and sporulation of Phytophthora ramorum on northern red oak and chestnut oak. J. Phytopathol. 159:516-521.

Tooley, P. W., and Kyde, K. L. 2007. Susceptibility of some Eastern forest species to Phytophthora ramorum. Plant Dis. 91:435-438.

Tooley, P. W., Kyde, K. L., and Englander, L. 2004. Susceptibility of selected ericaceous ornamental host species to Phytophthora ramorum. Plant Dis. 88: 993-999.

Trujillo, E. E. 1964. The effects of humidity and temperature on Phytophthora blight of taro. Phytopathology 55:183-188.

Turner, P. D. 1965. Behavior of Phytophthora palmivora in soil. Plant Dis. Rep. 49:135-137.

USDA-APHIS. 2012. List of Regulated Hosts and Plants Proven or Associated with Phytophthora ramorum (January 2012). United States Department of Agriculture-Animal and Plant Health Inspection Service. http://www. aphis.usda.gov/plant_health/plant_pest_info/pram/downloads/pdf_files/usdaprlist. pdf

Werres, S., Marwitz, R., Man In't veld, W. A., De Cock, A. W. A. M., Bonants, P. J. M., De Weerdt, M., Themann, K., Ilieva, E., and Baayen, R. P. 2001 Phytophthora ramorum sp. nov., a new pathogen on Rhododendron and Viburnum. Mycol. Res. 105:1155-1165.

Widmer, T. L. 2009. Infective potential of sporangia and zoospores of Phytophthora ramorum. Plant Dis. 93:30-35.

Zentmyer, G. A. 1961. Chemotaxis of zoospores for root exudates. Science 133: $1595-1596$ 